\title{
Frontier studies on fatigue, autonomic nerve dysfunction, and sleep-rhythm disorder
}

\author{
Masaaki Tanaka $^{1} \cdot$ Seiki Tajima $^{2} \cdot$ Kei Mizuno $^{3} \cdot$ Akira Ishii $^{1} \cdot$ Yukuo Konishi $^{2}$ • \\ Teruhisa Miike ${ }^{2} \cdot$ Yasuyoshi Watanabe $^{1,3}$
}

Received: 30 August 2015/Accepted: 1 September 2015/Published online: 29 September 2015

(C) The Author(s) 2015. This article is published with open access at Springerlink.com

\begin{abstract}
Fatigue is defined as a condition or phenomenon of decreased ability and efficiency of mental and/ or physical activities, caused by excessive mental or physical activities, diseases, or syndromes. It is often accompanied by a peculiar sense of discomfort, a desire to rest, and reduced motivation, referred to as fatigue sensation. Acute fatigue is a normal condition or phenomenon that disappears after a period of rest; in contrast, chronic fatigue, lasting at least 6 months, does not disappear after ordinary rest. Chronic fatigue impairs activities and contributes to various medical conditions, such as cardiovascular disease, epileptic seizures, and death. In addition, many people complain of chronic fatigue. For example, in Japan, more than one third of the general adult population complains of chronic fatigue. It would thus be of great value to clarify the mechanisms underlying chronic fatigue and to develop efficient treatment methods to overcome it. Here, we review data primarily from behavioral, electrophysiological, and neuroimaging experiments related to neural dysfunction as well as autonomic nervous system, sleep, and circadian rhythm disorders in fatigue. These data
\end{abstract}

Yasuyoshi Watanabe

yywata@riken.jp

Masaaki Tanaka

masa-t@msic.med.osaka-cu.ac.jp

1 Department of Physiology, Osaka City University Graduate School of Medicine, 1-4-3 Asahimachi, Abeno-ku, Osaka 545-8585, Japan

2 Hyogo Children's Sleep and Development Medical Research Center, Hyogo Rehabilitation Centre, Central Hospital 1070 Akebono-cho, Nishi-ku, Kobe, Hyogo 651-2181, Japan

3 RIKEN Center for Life Science Technologies, 6-7-3 Minatojima-minamimachi, Chuo-ku, Kobe, Hyogo 650-0047, Japan provide new perspectives on the mechanisms underlying chronic fatigue and on overcoming it.

Keywords Autonomic nervous system - Central nervous system · Circadian rhythm · Fatigue $\cdot$ Sleep

\section{Introduction}

Fatigue is an indispensable bio-alarm, without which we might drop into an unrecoverable exhaustive state, and in the most severe case, even die, referred to in Japanese as "Karoshi". It is likely that all people have experienced fatigue to some extent, and we know that this sensation decreases the efficiency of our daily tasks or studies. Thus, it is of great value to modern society for scientists to analyze the causes of fatigue and develop methods to quantify fatigue, with the goal of developing methods or therapies to afford better recovery from, and perhaps even avoidance of, severe chronic fatigue.

The following achievements had been made through previous projects: (1) elucidation of the brain regions and their neurotransmitter systems responsible for the fatigue sensation and chronic fatigue; (2) development of a variety of methods and scales to quantitatively evaluate the extent of fatigue; (3) development of animal models based on different causes of fatigue; (4) elucidation of molecular/ neural mechanisms of fatigue in humans and animals; and (5) invention of various methods or therapies to treat chronic fatigue and chronic fatigue syndrome (CFS). Many researches are now promoting large-scale research projects on the molecular/neural mechanisms of fatigue and chronic fatigue and are also attempting to develop the therapeutics and remedies to improve the fatigued state. Such solutions are expected to provide a better quality of life for fatigued 
individuals. Here, we review data primarily from behavioral, electrophysiological, and neuroimaging experiments related to neural dysfunction as well as autonomic nervous system, sleep, and circadian rhythm disorders in fatigue. These data provide new perspectives on the mechanisms underlying chronic fatigue and on overcoming it.

\section{Fatigue and changes in autonomic function (Fig. 1)}

\section{Autonomic function analysis}

Frequency analyses for $\mathrm{R}-\mathrm{R}$ interval variation of the electrocardiogram (ECG) or a-a interval variation of plethysmography (APG) are used with the maximum entropy method and fast Fourier transformation [1-3]. For frequency analyses, the low-frequency power component (LF) was calculated as the power within a frequency range of $0.04-0.15 \mathrm{~Hz}$, and the high-frequency power component (HF) was calculated as that within a frequency range of $0.15-0.4 \mathrm{~Hz}$. HF is vagally mediated [4-6], whereas LF originates from a variety of sympathetic and vagal mechanisms $[4,7]$. The ratio of LF power component/HF power component ( $\mathrm{LF} / \mathrm{HF}$ ratio) is considered to represent sympathetic activity [8].

\section{Acute fatigue and autonomic function}

Acute fatigue in healthy individuals can be induced by loading lengthy mental tasks, such as the 2-back task (working memory task), advanced trail making test (switching attention), and the kana pick-out test (KPT; divided attention), for $30 \mathrm{~min}$ to $8 \mathrm{~h} \mathrm{[9-11].} \mathrm{As} \mathrm{for} \mathrm{auto-}$ nomic function in the acute fatigue condition, decreased parasympathetic activity (low value of HF) and increased sympathetic activity (high value of $\mathrm{LF} / \mathrm{HF}$ ratio) have been observed in healthy volunteers following a 30-min series of fatigue-inducing mental tasks $[9,10]$. After a prolonged cognitive load for $8 \mathrm{~h}$, corresponding to a normal workday, we found that sympathetic hyperactivity (high value of LF/ HF ratio) based on decreased parasympathetic activity (low value of HF) was positively correlated with subjective fatigue level as evaluated by the visual analogue scale [11]. These findings indicate that acute mental fatigue is characterized by an increase in sympathetic nerve activity and a decrease in parasympathetic nerve activity.

\section{Sub-acute fatigue and autonomic function}

Sub-acute levels of fatigue can be evaluated using Chalder's fatigue scale, a paper-and-pencil questionnaire [12]. A Japanese version has also been developed, and the reliability and validity of the Japanese version to evaluate the severity of daily fatigue have been confirmed previously $[13,14]$. Levels of sympathetic nerve activity (LF and LF/ $\mathrm{HF}$ ratio) and parasympathetic nerve activity (HF) of healthy adults have been positively and negatively associated, respectively, with scores on Chalder's fatigue scale [10]. These findings indicate that enhanced sympathetic nerve activity based on decreases in parasympathetic nerve activity is common in the acute and sub-acute fatigue conditions.

\section{Chronic fatigue and autonomic function}

CFS is a disease characterized by chronic, profound, disabling, and unexplained fatigue [15]. Fatigue-related alterations of autonomic nervous system activities have been reported in adults with CFS [16-18]. Decreased parasympathetic nerve activity and increased sympathetic activity have also been observed in patients with CFS. Yamaguti et al. [18] reported that the sympathetic hyperactivity level of patients with CFS was dependent on the severity of symptoms as evaluated by a performance status test. Not only adults with CFS but also children and adolescents with CFS have been observed to have sympathetic hyperactivity based on decreased parasympathetic nerve activity [19]. These findings indicate that sympathetic

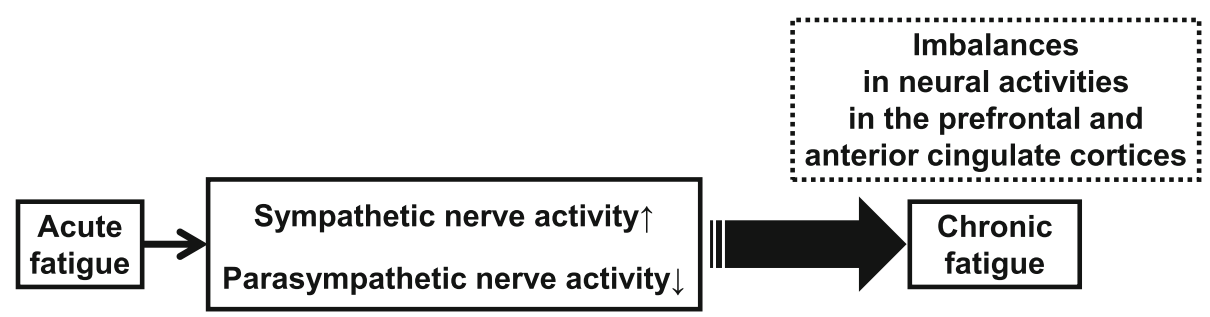

Fig. 1 Autonomic function can be evaluated by electrocardiography or plethysmography. Frequency analysis of the data obtained from electrocardiography and accelerated plethysmography have revealed that enhanced sympathetic nerve activity based on a decrease in parasympathetic nerve activity is common in acute, sub-acute, and chronic fatigue. Alteration of autonomic function may result in changes and imbalances in neural activities in the central autonomic network of the brain, including the prefrontal and anterior cingulate cortices. Several interventions for the alleviation of fatigue are effective in decreasing sympathetic nerve activity. Evaluation of autonomic function contributes to investigating the effects of interventions for recovery from fatigue 
hyperactivity based on low parasympathetic nerve activity is common in acute, sub-acute, and chronic fatigue.

\section{Autonomic alterations as mechanisms of fatigue}

In terms of autonomic nerve function, the central autonomic network that controls sympathetico-vagal balance consists of the orbitofrontal cortex (OFC), medial prefrontal cortex (PFC), anterior cingulate cortex (ACC), insular cortex (IC), amygdala, bed nucleus of the stria terminalis, hypothalamus, periaqueductal gray matter, pons, and medulla oblongata $[20,21]$. The ACC plays a particularly crucial role in the central control of sympathetico-vagal balance [22]. There are anatomical and functional connections between the dorsolateral PFC (DLPFC) and medial PFC, including the ACC and the OFC [23-26]. Sympathoexcitatory subcortical threat circuits are normally under the inhibitory control of the medial PFC [27-29].

In an experimental setting, acute mental fatigue of healthy volunteers has been produced by a prolonged load of executive function tasks such as working memory and attention control tasks [9-11]. Several studies using functional magnetic resonance imaging (fMRI) have reported that during prolonged mental tasks lasting $1-2 \mathrm{~h}$, activation of the brain regions related to mental task processing was gradually reduced [30,31]. During fatigue-inducing mental tasks, the PFC, including the ACC, which is associated with the processing of executive functions such as verbal working memory, visuospatial working memory, and divided attention in the 2-back test, advanced trail making test, and KPT, respectively, may be continuously activated [32]. However, these prefrontal activities may be gradually reduced with loading time. As with the medial OFC, this region is associated with fatigue sensation [33]. The medial OFC was shown to exhibit a positive correlation in activity with the subjective sensation of fatigue, measured immediately after each positron emission tomography (PET) scan with $\mathrm{H}_{2}^{15} \mathrm{O}$ [a probe for regional cerebral blood flow (rCBF)] for 1.5 h. [33]. These results suggest that acute mental fatigue induces changes and imbalances in neural activities of the regions involved in the central autonomic network; thus, it is difficult to control the inhibitory capacity of the sympathoexcitatory response. Evidence such as lowered cerebral activity in the PFC during fatigueinducing tasks [34] and a bilateral reduction of gray-matter volume in the prefrontal cortices of patients with CFS [35] suggests that individuals with CFS may exhibit anatomical and functional alterations in the PFC. Because the role of the PFC is essential in active tonic inhibition of sympathoexcitatory threat circuits, such alterations in the PFC seen in patients with CFS could be expected to lead to a decrease in parasympathetic drive, defaulting to a sympathetically driven system. Therefore, it is possible that an accumulation of mental fatigue (sub-acute mental fatigue and chronic fatigue) in healthy people induces a prolonged deterioration of autonomic activity through anatomical and functional alterations of the PFC.

\section{Application of autonomic function in clinical and industrial settings}

To measure autonomic nerve function and fatigue levels, both in clinical and industrial settings, better experimental designs, including briefer mental tasks and more sensitive measurement methods for detecting changes in sympathico-vagal balance, are needed. We designed a 16-min period of ECG measurement during a resting state before the KPT, with participants' eyes open for 3 min and closed for $3 \mathrm{~min}$, during the KPT for $4 \mathrm{~min}$, and during a resting state after the KPT with their eyes open for $3 \mathrm{~min}$ and closed for $3 \mathrm{~min}$. We investigated the correlation between fatigue sensation and alterations of autonomic nerve activity using this protocol to perform the KPT in healthy volunteers [36]. The KPT is frequently used as a fatigueevaluation test in both children and adults [19, 36, 37]. A baseline fatigue sensation, measured by a visual analogue scale before the experiment, was associated with an increase in sympathetic nerve activity (LF/HF ratio) during the KPT. The LF/HF ratio during the post-KPT resting state with eyes open tended to be greater than the ratio during the KPT and was correlated with fatigue sensation. Fatigue sensation was correlated negatively with parasympathetic nerve activity (HF) during the post-KPT rest period with eyes open. These results suggest that a brief mental task can be used to evaluate changes in autonomic nerve activity with fatigue if the eyes-open condition is used. Therefore, the methods described here are useful for assessing the association between fatigue sensation and autonomic nerve activity involved in fatigability using a brief cognitive test.

\section{Anti-fatigue and autonomic function}

To prevent healthy individuals from suffering from chronic fatigue, early intervention and evaluation of the effects of intervention are important. For this purpose, autonomic functions may be useful as objective physiological markers for acute and chronic fatigue. We previously studied antifatigue effects on acute mental fatigue of healthy adults during bathing normally and during bathing with water containing micro-bubbles. A sensation of reduced fatigue, as detected by the visual analogue scale after the fatigueinducing mental task for $4 \mathrm{~h}$, was negatively associated with sympathetic nerve activity (LF/HF ratio) only in the micro-bubble bathing condition. These findings suggest 
that micro-bubble bathing is effective in preventing an increase in acute mental fatigue [38]. An equivalent mixture of $0.03 \%$ cis-3-hexenol and $0.03 \%$ trans-2-hexenal diluted with triethyl citrate is known to have a healing effect on psychological damage caused by stress. The behavioral studies described above in humans and monkeys revealed that hexenol/hexenal prevented the prolongation of reaction time caused by fatigue [39]; the ACC was activated by the fragrance of hexenol/hexenal. This finding suggests that an increase in $\mathrm{rCBF}$ using $\mathrm{H}_{2}^{15} \mathrm{O}$ as detected by PET in the ACC caused by the fragrance of hexenol/ hexenal may contribute to its healing effects observed in monkeys [40]. In a human study, the task performance of healthy volunteers did not decrease and sympathetic nerve activity did not increase by sniffing the aroma of hexenol/ hexenal during prolonged performance of the advanced trail making test, indicating that this fatigue-alleviation effect might occur via an autonomic function, such as a healing effect on the sympathetic nervous system caused by stimulating the activity of the central autonomic network, especially the cingulate cortex [39].

Sympathetic hyperactivity based on a decrease in parasympathetic nerve activity is common in acute, subacute, and chronic fatigue. This autonomic function alteration is related to a decrease in the brain function of the central autonomic network. To prevent the accumulation of fatigue, interventions on recovery from fatigue via normalization of sympathetic hyperactivity are important. Findings from studies done by a collaboration of industry, academia, and government may lead to the development of an anti-fatigue solution.

\section{Role of sleep and circadian rhythm in fatigue recovery (Fig. 2)}

\section{Sleep features in individuals with CFS or chronic fatigue state}

CFS is a medically unexplained disabling illness characterized by persistent relapsing fatigue of at least 6 months' duration with low activity levels. Post-exertion malaise, neurocognitive dysfunction, infection-related symptoms, autonomic dysfunctions, and sleep disturbances are also major features of CFS. Six studies reported no CFS specific findings in polysomnography (PSG) or actigraphy in contrast with CFS patients' significant sleep complaints [4146]. Fatigue or pain was well correlated with sleep disturbances and daily activity in patients with CFS or a CFSrelated disorder, such as fibromyalgia [43, 47-49]. Interestingly, there was a weak correlation between fatigue score and sleepiness score in individuals without fatiguerelated disorders [50]. Under ambulatory monitoring

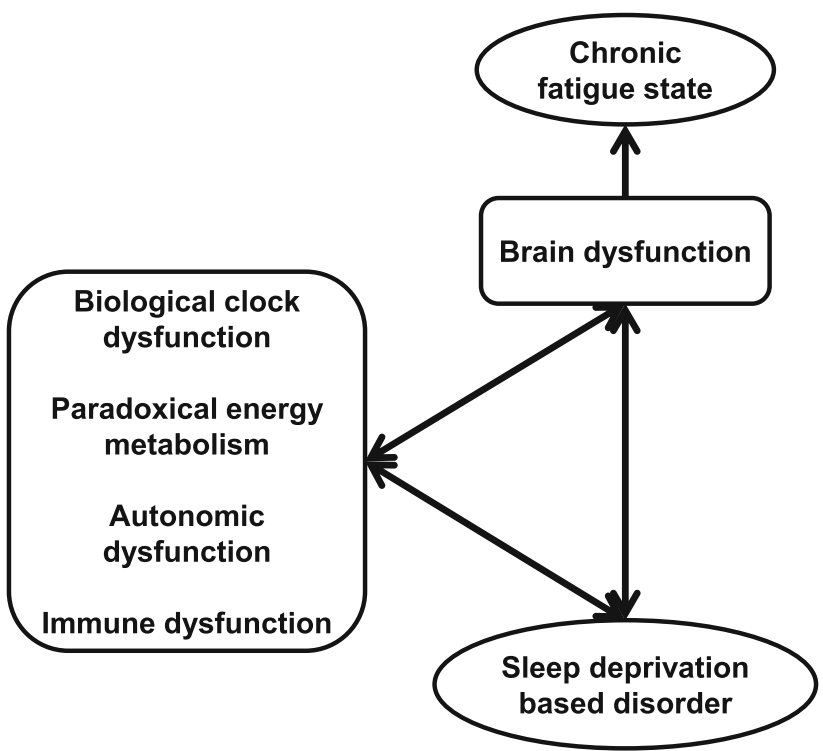

Fig. 2 Chronic fatigue state induced by sleep deprivation. Accumulation of sleep deprivation caused brain dysfunction with/without biological dysfunctions. Fundamental biofunctions (biological clock, energy metabolism, autonomic activity, and immune system), sleep disorders, and brain functions interacted with each other and created negative chains. Chronic fatigue state was observed as the output of brain dysfunctions

conditions using home-based PSG or actigraphy, patients with CFS showed significant longer bedtime sleep, longer awake time after sleep onset, and less efficient sleep [5155]. Individuals with CFS had a high incidence of undiagnosed primary sleep disorders [56, 57]. This result strikes a note of warning for physicians. Eight studies reported objective abnormalities in patients with CFS in terms of respiratory index, electroencephalographic power spectrum, and sleep-awake switching dynamics [58-65]. Gotts et al. showed that patients with CFS were divided into four clusters by sleep features based on hierarchical cluster analysis [66]. Those dynamics-based and cluster analysis results may reveal the heterogeneity of CFS pathophysiology and a new viewpoint regarding an analytical approach. It was also noted that total Pittsburgh sleep quality index score might not be suitable for patients with CFS [67, 68]. There were no significant actigraphic or polysomnographic differences between patients with CFS and a control group [49, 65, 68].

\section{Physical exercise effects on CFS}

To examine the effect of exercise on post-exertional exacerbations, Ohashi et al. performed actigraphic circadian analysis for approximately 1 week before and after performing a maximal treadmill test in the patients with CFS and healthy controls. In that study, lengthening the mean circadian period induced by one period of exercise 
remained several days in patients with CFS [69]. No significant PSG index change was observed after exercise load [70]. However, in terms of sleep stage transition dynamics, significant decreases in sleep stage continuity caused by exercise were revealed [71].

\section{Circadian aspect of sleep and fractal features of diurnal and nocturnal activity in CFS}

Dim-light, melatonin-onset delay was observed repeatedly in patients with CFS [72, 73, 75]. Dissociation of bodytemperature and melatonin secretion circadian rhythms were also found in patients with CFS [74]. Fluctuations of circadian melatonin secretion and core body temperature were reported in patients with CFS [72, 75, 76]. From a therapeutic point of view, abnormal circadian oscillation of core body temperature, plasma melatonin, cortisol, and $\beta$ endorphin levels were improved by treatment with methylcobalamin and melatonin in a patient with pediatric CFS [72].

Ohashi et al. found a significant diurnal rest-action structure change in patients with CFS [77]. The fractal feature change of physical activity was confirmed in Japan [78], and also in patients with pediatric CFS [79].

\section{Clock gene expression in pediatric CFS}

We reported that accumulation of sleep deprivation altered biological rhythm can lead to pediatric CFS [72, 76, 79]. Based on these findings, we hypothesized that biological clock modulation caused pediatric chronic fatigue pathophysiology. To address this hypothesis, Takimoto et al. performed clock gene expression analysis in patients with pediatric CFS [80]. That study suggested that the monitoring of human clock genes in whole blood cells, which may be functionally important for the molecular control of the circadian pacemaker as well as in the suprachiasmatic nucleus, might be useful for the evaluation of internal synchronization.

\section{Nocturnal autonomic nerve activity in CFS}

Less nocturnal vagal tone in patients with CFS has been reported frequently [13, 17, 81, 87]. Correlation between fatigue severity and a diurnal sympathetic activity was also found [82]. Diurnal sympathetic hyperactivity may cause an accumulation of the fatigue state and decreased vagal tone during sleep may cause unrefreshing sleep.

\section{Brain imaging and cognitive impairment in CFS}

A significant decrease of blood flow in the frontal, temporal, and occipital lobes, and a decrease of metabolic levels in the frontal lobe were observed in patients with pediatric CFS [83, 84]. This suppressed cerebral blood flow and energy metabolism may be relevant to cognitive dysfunction. Recently, significant progress has been made in the field of brain functional imaging. Ideas for connecting and using these findings are expected in the near future.

In patients with pediatric CFS, abnormally prolonged P300 latency to target stimuli might be associated with learning disability, and abnormally exaggerated P300 amplitude to non-target stimuli might be associated with hypersensitivity [19]. Those subtypes, divided by cognitive function, were correlated with fatigue state severity. In contrast to pediatric findings, napping, particularly in the afternoon, was associated with poorer cognitive functioning and more daytime sleepiness in adult patients with CFS [85]. These findings have clinical implications for symptom management strategies.

\section{Oxidative stress and cytokines in CFS}

Methemoglobin was found to be the major component correlated with variation in symptom expression in patients with CFS; symptoms included fatigue, musculoskeletal symptoms, pain, and sleep disturbances. Variations in levels of malondialdehyde and 2,3-diphosphoglycerate were also correlated with variations in cognitive symptoms and sleep disturbances [86]. These results suggest that oxidative stress due to excess free radical formation is a contributor to the pathology of CFS and is associated with symptom presentation.

mRNA expression of cytokines was suppressed under the condition of sleep disturbance in patients with pediatric CFS [87]. A major hypothesis regarding the cause of CFS is immune dysregulation such as upregulation of proinflammatory cytokines. There are discrepancies between results of immunological studies in patients with pediatric CFS and a major hypothesis in adult CFS pathogenesis. Nakamura et al. reported that physical exertion or sleep deprivation did not produce clinically significant upregulation of proinflammatory cytokines [88]. This latter result complicates the discrepancies found. Further studies will be needed.

\section{Peripheral energy metabolism in pediatric CFS}

Fatigability in patients with CFS seems to be based on down-regulation of energy metabolism clinically. To address this clinical question, Iwatani et al. performed the oral glucose tolerance test to measure glucose metabolism in patients with pediatric CFS [89]. Results indicated that glucose dysregulation in patients with pediatric CFS appeared to be caused by emotional distress. Multiple 
factors, including autonomic nervous system disorders, derangement of neuropeptides in the hypothalamus, and hormonal imbalances, may also affect glucoregulatory metabolism, predisposing these patients to hyperglycemia. They concluded that the glucoregulatory system compensates for decreased blood flow to the brain by increasing blood glucose concentrations, thereby providing sufficient glucose as the primary energy source used during normal brain metabolism.

\section{Role of sleep and circadian rhythm in fatigue recovery}

PSG assessment based on conventional approaches show no useful information to assess the pathophysiology of CFS. Physiological data, for example, electroencephalograms (EEGs), electrocardiograms, physical activity, and core body temperature, should be assessed by new approaches such as dynamic system analysis.

Sleep deprivation has a high impact on chronic fatigue pathophysiology, especially in childhood. Accumulation of sleep deprivation alters the biological rhythm. We have reported that alterations in biological rhythm increase circadian biological dysfunctions, for example, endocrine, energy metabolism, autonomic activity, and neurocognitive dysfunctions.

It is still a challenge to recover from CFS today. Prevention of CFS is the only way to minimize the social impact of this disorder. The relationship between chronic fatigue pathogenesis and sleep deprivation is apparent. Therefore, Miike, the director of Hyogo Children's Sleep and Development Medical Research Center (HCSDMRC), and his colleagues keep challenging healthcare providers to prevent children's sleep deprivation via sleep education not only in schools but also by region. Five years of intervention has been shown to prevent school non-attendance completely in some areas. However, prevention of school non-attendance is not equal to prevention of pediatric CFS. Miike proposes to extend this 'sleep well action' to infants and their families. The issue then becomes identifying the risk factors of future sleep disturbances for infants. The key was in the HCSDMRC clinical experiences. All infants who visited the HCSDMRC clinic due to sleep disturbances were irritable $(78.6 \%)$ or sluggish $(21.4 \%)$ in the neonatal period. Interestingly, $66 \%$ of those who were sluggish changed to the irritable state in the first year of life. As the result of our ongoing clinical research, we hypothesize that those unusual states in the neonatal period are early predictors of autism spectrum disorder. Based on clinical evidence, we propose that irritable or sluggish newborns should be followed by medical specialists of pediatric sleep medicine.

\section{Neural mechanisms of fatigue}

\section{Acute physical fatigue and the central nervous system}

When subjects are physically fatigued, they increase voluntary efforts to increase the motor output from the primary motor cortex (M1) to compensate until the task requires a maximal effort [90]. Using an electrophysiological technique, a facilitation system to increase motor output from the M1 against physical fatigue was suggested [91]. While participants were performing a maximum voluntary contraction (MVC), a short-latency excitatory electromyography (EMG) response in the M1 increased, indicating increased excitation. Because this change was unaffected by the manipulation of afferent inputs, this was considered to be the result of an enhanced voluntary drive to the M1 via activation of the facilitation system [91].

This facilitation system has also been described in neurophysiological and neuroimaging studies, during fatigue-inducing submaximal physical task trials. Increased activations (area and intensity) in the contralateral M1 have been observed in EEG [92, 93], PET [94, 95], and fMRI [96-99] studies, which matched the EMG signals [96] until the activations reached the maximum level. The increase in the contralateral M1 suggests recruitment of inactive neurons, and this recruitment may result in an increase in the drive to the target muscles but can also activate other nontarget muscles. Because increases in intensity across EEG, PET, and fMRI studies correlate with excitatory changes in the local field potentials $[100,101]$, the increase in intensity suggests increased excitatory input and sensory processing, and subsequent enhanced corticomotor drive to the target muscles by the contralateral M1.

The facilitation system may include the ipsilateral M1. While participants performed submaximal voluntary contractions, the fMRI activation volume in the ipsilateral M1 exhibited a steady increase [96]. Because 7-8\% of M1 neurons are associated with ipsilateral movements [102], additional recruitment of the cortical motoneurons from the ipsilateral side may work to compensate for central nervous system fatigue.

In addition to the contralateral and ipsilateral M1, activation of other brain regions has been shown during submaximal physical tasks, and these areas may be involved in the facilitation system. EEG signals showed location shifts toward the ipsilateral, anterior, and inferior sides, indicating augmentation in the ipsilateral sensorimotor, prefrontal, orbitofrontal, and anterior cingulate areas [93], and increased EEG responses in the bilateral supplementary motor area (SMA) have been observed [92]. Similar activation patterns have been shown in rCBF responses 
assessed using PET, magnetic responses using magnetoencephalography (MEG), and blood oxygen level-dependent (BOLD) responses using fMRI. Increases in the rCBF response in the bilateral SMA, ACC, PFC, basal ganglia (BG), and thalamus (TH) $[94,95]$, in the magnetic responses in the ipsilateral sensorimotor area and PFC [103-105], and in the BOLD responses (area and intensity) in the bilateral SMA, ACC, and PFC [96, 99] were shown during the time course of submaximal motor tasks.

Based on the results of these electrophysiological and neuroimaging studies and the knowledge of neural interconnections [106], we proposed a neural pathway or circuit that constitutes the facilitation system to increase the motor output from the M1 to compensate for the effects of physical fatigue: the neural circuit or re-entrant loop that interconnects the limbic system, BG, TH, OFC, PFC, ACC, SMA, and M1, constitutes the facilitation system and an increase in the motivational input to this facilitation system enhances the SMA and then M1 to increase the motor output to muscles via the spinal cord [107].

\section{Acute mental fatigue and the central nervous system}

The facilitation system of mental fatigue has also been described in behavioral, electrophysiological, and neuroimaging studies of fatigue-inducing submaximal mental tasks [9, 108-118]. Some reports suggest that cognitive task performance is maintained during the mental task trials, even when participants are fatigued [9, 108-110, 113, 115]. For example, cognitive task performance assessed by reaction time and accuracy did not change over time in a fatigue-inducing mental task session [9, 110, 113, 115]. The advanced trail making test (ATMT) [119] was used to determine whether participants were mentally fatigued. In the ATMT, circles numbered from 1 to 25 are randomly located on the display of a personal computer, and participants are required to use a computer mouse to click the center of the circles in sequence, starting with circle number 1 . The number of errors on the ATMT and the subjective level of mental fatigue was increased after the fatigue-inducing mental task trials. These findings demonstrate that participants were mentally fatigued after the mental task, and suggest that cognitive performance was not altered by a compensatory mechanism, that is, the mental facilitation system [113].

As described previously, frequency domain analyses of electrocardiography $\mathrm{R}-\mathrm{R}$ wave intervals can be used to evaluate activity of the sympathetic nervous system [8], and findings indicate that the sympathetic nervous system is active during a fatigue-inducing mental task session [9, 11]. Increased motivation or mental effort has been associated with increased sympathetic nervous system activation [120, 121]; therefore, the increase in sympathetic nervous system activity during the mental task session may reflect an increase in the contribution of motivation or mental effort to the maintenance of cognitive task performance in the presence of mental fatigue. Considerable evidence supports this assumption; for example, an increased level of motivation resulted in an improvement of cognitive task performance during a fatigue-inducing mental task [30].

Oscillatory brain rhythms are considered to originate from synchronous synaptic activities of a large number of neurons [122]. Synchronization of neural networks may reflect integration of information processing, and continuously interacting dynamic neural networks are assessed through the synchronization of oscillations at particular time-frequency bands [123]. Such synchronization processes can be evaluated using MEG time-frequency analyses. Alpha-band $(8-13 \mathrm{~Hz}$ ) power in the frontal cortex was lower after the fatigue-inducing mental task session than before [113]. Large-scale, rhythmic oscillations in brain activity at alpha-band frequencies are generated by interactions between thalamo-cortical neurons and GABAergic ( $\gamma$-aminobutyric acid) cells in the thalamic reticular nucleus [124, 125]. Therefore, suppressed spontaneous alpha-band power, that is, desynchronization due to intrinsic events in the frontal cortex caused by mental fatigue suggests an overactivation of the thalamic-frontal circuit. Considering that task performance was maintained during the fatigue-inducing mental task trials, this thalamic-frontal circuit is a candidate neural substrate for the mental facilitation system related to motivation or mental effort [113].

A physical task with moderate intensity improved cognitive function and enhanced functional near-infrared spectroscopy response in the frontal area [126]. This finding implies that the physical facilitation system shares common neural substrates with the mental facilitation system; that is, activation of the physical facilitation system may enhance the mental facilitation system through activation of common neural networks, including the frontal area [127]. The physical facilitation system is a reentrant neural circuit that interconnects the limbic system, BG, TH, OFC, DLPFC, ACC, SMA, and M1 [107]. The results of studies using event-related potentials indicate that evaluation of predicted rewards and potential risks of actions are central to mental fatigue, and the evaluation system was considered to consist of a neural circuit that interconnects the limbic system, BG, TH, OFC, DLPFC, and ACC [128]. In addition, resting $\mathrm{rCBF}$ assessed using fMRI in the TH and frontal cortex was positively associated with cognitive task performance during mental fatigue [129]. Hence, the mental facilitation system may be a neural circuit that interconnects the limbic system, BG, $\mathrm{TH}$, and frontal cortex, and an increase in motivational 
input to this facilitation system may activate the system and compensate for the effects of mental fatigue [130].

\section{Chronic fatigue and the central nervous system}

Dysfunction of the facilitation system in subjects with chronic fatigue has been indicated through alterations of cognitive function. During Stroop trials, color and word dimensions activate the associated responses, resulting in a conflict between the activated responses and an increased likelihood of error [131]. This conflict is proposed to activate a conflict monitor in the ACC, which in turn engages the control function in the DLPFC. The engagement of the DLPFC increases attention on subsequent trials, resulting in improved performance [132]. Because the level of chronic fatigue was positively associated with the error rate of the Stroop trials [115], chronic fatigue might cause deterioration in response inhibition through impaired functions in the ACC and/or DLPFC.

It was proposed that fatigue associated with neurological disorders occurs due to a failure in the facilitation system $[133,134]$. In a 2- $\left[{ }^{18}\right.$ F $]$ fluoro-2-deoxy-D-glucose (FDG) PET study, subjects with fatigue from multiple sclerosis (MS) showed reduced FDG uptake in the brain regions involved in the striatal-thalamic-frontal circuit [135]. In MS patients without impaired hand function, greater fMRI responses relative to healthy participants have been reported during simple hand movements in the contralateral M1 [136, 137], while after fatigue-inducing handgrip trials, these MS patients did not show greater activation in this brain region although healthy participants showed greater activation [137]. These results can be interpreted as follows: dysfunction of the facilitation system contributes to chronic fatigue in these patients. As for CFS, even a minor activity leads to significant worsening of fatigue [15], although these patients have normal or near-normal aerobic capacity [138] and muscle function [139]. Patients with CFS showed anatomic and/or metabolic impairments in the brain regions involved in the facilitation system, that is, the BG [140], OFC [35, 141-143], PFC [141, 142, 144], and ACC [141, 142]. Thus, dysfunction of the facilitation system seems to contribute to the pathophysiology of chronic fatigue-related diseases or syndromes.

Enhancement of the facilitation system can cause neural activation (higher level of and wider area of neural activation) $[23,29,145-148]$ and induce the release of large quantities of excitatory amino acids, such as glutamate and aspartate. Released glutamate binds to different receptors; the main one being the $N$-methyl-D-aspartate subtype, whose activation causes mobilization of free cytosolic calcium. Excessive intracellular calcium concentrations lead to over-activation of certain calcium-dependent enzymes, resulting in the generation of proinflammatory cytokines, chemokines, inflammatory mediators, and reactive oxygen and nitrogen species to cause oxidative stress, inflammation, and energy deficiency [149-158]. Hence, repetitive and prolonged overwork and/or stress without sufficient recovery to enhance the facilitation system seem to induce oxidative stress, inflammation, and energy deficiency in the central nervous system and cause neural damage followed by dysfunction of the facilitation system. Chronic activation of sustained oxidative stress [69], inflammation [159], and secondary mitochondrial dysfunction and impaired energy metabolism [160] in the central nervous system are also considered to be involved in the pathophysiology of CFS.

Based on these findings, we present here a hypothetical model of developing chronic fatigue (Fig. 3) [16, 161165]. When subjects are acutely fatigued through overwork and/or stress, they progressively increase their voluntary effort to maintain their performance to compensate for acute fatigue until the work requires a maximal effort; at that point, the facilitation system in the central nervous system is activated (intensity and area) to overcome acute fatigue. The facilitation system consists of a re-entrant neural circuit that interconnects the limbic system, BG, $\mathrm{TH}, \mathrm{OFC}, \mathrm{PFC}$, and ACC, and a motivational input activates this system. In addition, as subjects become acutely fatigued, an alarm signal to take a rest (inhibitory system) is activated to avoid further fatigue. The inhibition system consists of a neural pathway that involves the IC and PCC. We propose that after repetitive and prolonged overwork and/or stress that activates the facilitation system without sufficient recovery, the facilitation system dysfunctions, through neural damage to it caused by oxidative stress, inflammation, and energy deficiency. Subjects express impaired information processing in the central nervous system. In addition, we propose that repetitive and prolonged overwork and/or stress cause central sensitization and classical conditioning of the inhibition system. This conditioned inhibition system occurs in subjects with chronic fatigue, resulting in a long-lasting alarm signal to take a rest and a severe sustained fatigue sensation and functional disabilities.

\section{Neural mechanisms of fatigue sensation}

\section{Fatigue sensation}

Fatigue sensation acts as a biological alarm to rest to maintain homeostasis and constitutes the inhibition system of fatigue. However, if the fatigue sensation is over-activated, such as occurs through classical conditioning and/or central sensitization, a decline in the performance of mental and physical activities may occur [165]. Therefore, 


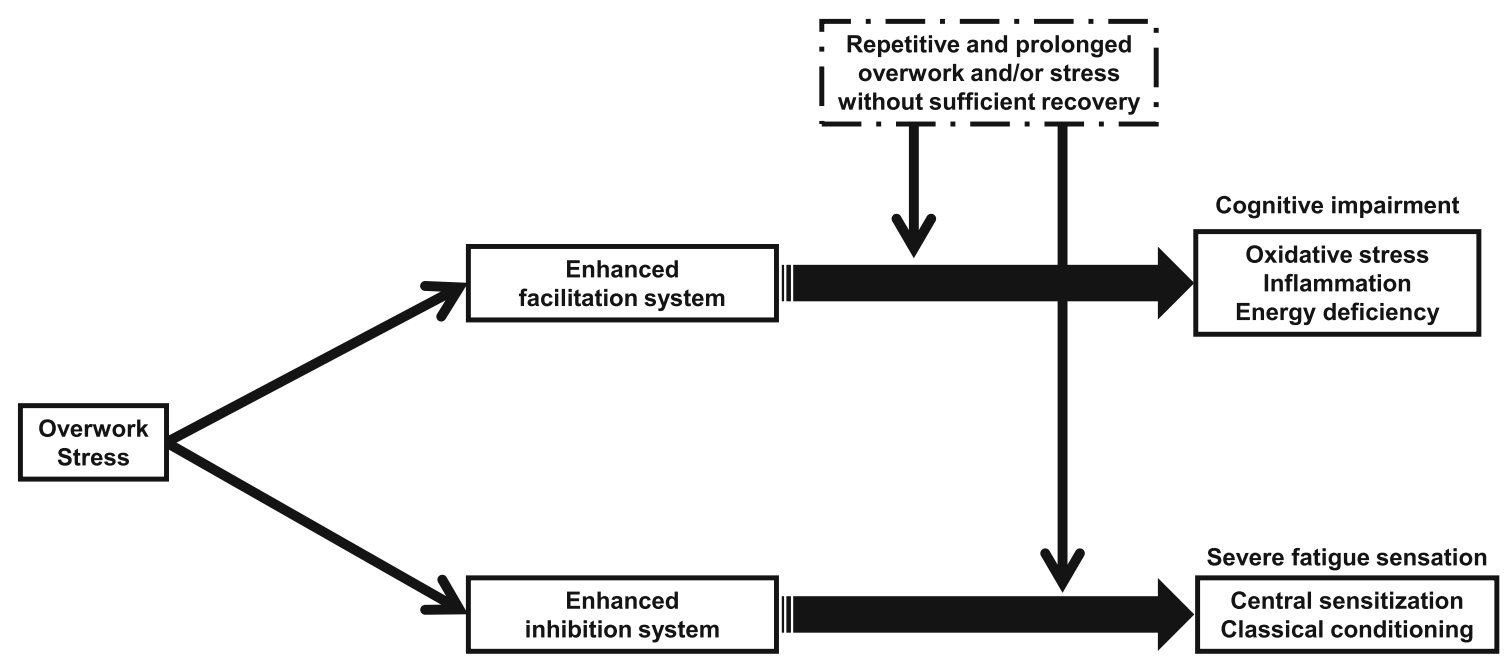

Fig. 3 Hypothetical model of the development of chronic fatigue. When subjects are acutely fatigued through overwork and/or stress, they progressively increase their voluntary effort to maintain their performance to compensate for acute fatigue until the work requires a maximal effort. At that point, the facilitation system in the central nervous system is activated to overcome acute fatigue. The facilitation system consists of a re-entrant neural circuit that interconnects the limbic system, basal ganglia, thalamus, orbitofrontal cortex, prefrontal cortex, and anterior cingulate cortex, and a motivational input activates this system. In addition, as subjects become acutely fatigued, an alarm signal to take a rest (inhibitory system) is activated to avoid further fatigue. The inhibition system consists of a neural

it is important to understand the neural mechanisms of fatigue sensation and test whether fatigue sensation can be caused through classical conditioning and/or central sensitization.

An MEG study related to the mirror system of fatigue sensation has been reported [166]. Twelve healthy male volunteers participated in this study and viewed 80 pictures with fatigued facial expressions and those with neutral facial expressions in a randomized order. Because there have been several reports showing that seeing emotional changes in others activates the brain regions involved in experiencing similar emotions [167-173], it is hypothesized that the brain regions activated when they viewed the fatigued facial expressions may be candidate brain regions related to the neural mechanisms of fatigue sensation. In fact, the equivalent current dipole (ECD) in the PCC was observed in 9 of 12 participants, and the ECD in the IC was observed in 3 of 12 participants only when they viewed the fatigued facial expressions, suggesting that the PCC and the IC are the candidate brain regions related to the neural mechanisms of fatigue sensation [166]. Because it has been reported that the PCC is involved in self-reflection or selfmonitoring [174-176], the neural substrates related to selfevaluation of the level of physical and mental fatigue were pathway that involves the insular and posterior cingulate cortices. After repetitive and prolonged overwork and/or stress that activates the facilitation system without sufficient recovery, the facilitation system dysfunctions, through neural damage to it caused by oxidative stress, inflammation, and energy deficiency. Subjects express impaired information processing in the central nervous system. In addition, repetitive and prolonged overwork and/or stress cause central sensitization and classical conditioning of the inhibition system. This conditioned inhibition system occurs in subjects with chronic fatigue, resulting in a long-lasting alarm signal to take a rest and a severe sustained fatigue sensation and functional disabilities

examined using MEG. Ten healthy male volunteers participated in a study that examined the neural substrates related to self-evaluation of the level of physical fatigue. When they self-evaluated the level of fatigue of their right hand, the ECD in the PCC was observed in 9 of 10 participants. On the other hand, when they directed their attention to their right hand as a control condition, the ECD in the PCC was observed in 2 of 10 participants. In addition, the intensity of the ECD in the PCC observed in relation to the self-evaluation of the level of physical fatigue was positively associated with the extent to which fatigue of the right hand was successfully evaluated. These results suggest that the activation in the PCC was related to the self-evaluation of the level of physical fatigue [177]. In the next study, the neural substrates related to self-evaluation of the level of mental fatigue were examined. Fourteen healthy male volunteers participated in this study. They performed 90 evaluation trials and 90 control trials in a randomized order. In the evaluation trials, they were asked to self-evaluate the level of their mental fatigue. The control trials were resting trials in which they were asked to do nothing. The ECD in the PCC was observed in 7 of 14 participants when they self-evaluated the level of their mental fatigue, although it was observed in only 1 of 14 
participants when they performed the control trials, suggesting that the activation in the PCC was also related to self-evaluation of the level of mental fatigue [178]. It has been shown that the PCC is not only involved in the neural mechanisms of fatigue sensation but is also involved in the neural mechanisms of making decisions in the presence of fatigue [179]. If individuals do not rest, despite the signs of fatigue, they may experience overwork, which may be a starting point of chronic fatigue as discussed later. Therefore, the decision of whether or not to rest based on the level of fatigue is important. Fifteen healthy male volunteers participated in this study. They performed 1200 reverse Stroop test trials and were intermittently asked whether to take a rest or not to maintain task performance; neural activities related to making decisions to rest were assessed. When they made decisions to rest, a decreased $4-8 \mathrm{~Hz}$ band power was observed in the PCC, and this decreased $4-8 \mathrm{~Hz}$ band power in the PCC was positively associated with the subjective level of fatigue caused by performing the experiment. As for the IC, it has been reported that the IC is involved in mental effort evaluation in an fMRI study in which the participants rated their mental effort investment required for performing 1-, 2-, and 3-back tests [180]. These findings suggest that the PCC and IC are involved in the neural mechanisms of fatigue sensation to self-evaluate the level of fatigue, and that the PCC plays an important role in making decisions to take a rest in the presence of fatigue.

\section{Classical conditioning of fatigue sensation}

It has been reported that classical conditioning related to fatigue took place in rats [181]. In this study, rats received paired conditioned and unconditioned stimuli. Feeding of a sucrose solution was used as a conditioned stimulus, and intraperitoneal injection of a synthetic double-stranded RNA, polyriboinosinic:polyribocytidylic acid (poly I:C), was used as a unconditioned stimulus. Because the poly I:C injection has been shown to be related to decreased spontaneous activity on the running wheel, injection of the poly I:C was used to make the rats fatigued [182-184]. After 4 days of this conditioning, the rats showed decreased spontaneous activity only when given the sucrose solution.

As it is hypothesized that the fatigue sensation induced by classical conditioning can be a cause of chronic fatigue [165], it is important to examine whether the fatigue sensation can be classically conditioned in humans and to clarify the neural mechanisms related to the classical conditioning of fatigue sensation in case it occurs. In fact, it has been shown that mental and physical fatigue sensation can be classically conditioned in humans in experimental settings. Ten healthy male volunteers participated in a study that examined whether mental fatigue sensation can be classically conditioned [185]. On the first day, MEG was recorded for $6 \mathrm{~min}$ while listening to metronome sounds (first MEG session), and then participants performed the 2-back test for $60 \mathrm{~min}$ as a conditioning session. Because it has been reported that performing the 2-back test for $30 \mathrm{~min}$ induced significant levels of the fatigue sensation $[9,10]$, we started the metronome sounds $30 \mathrm{~min}$ after the 2-back test started. On the second day, MEG was recorded again while listening to the metronome sounds (second MEG session). The level of the fatigue sensation caused by the metronome sounds in the second MEG session was significantly higher than that in the first MEG session, suggesting that the classical conditioning of mental fatigue sensation took place. An ECD analysis was performed for the MEG data from eight participants because the MEG data from two participants were contaminated with magnetic noise and excluded from the analysis. The ECD in the IC was observed in 6 of 8 participants and that in the PCC was observed in 4 of 8 participants only in the second MEG session. Because these magnetic responses were observed only in the second MEG session, these magnetic responses were thought to be involved in the neural mechanisms of fatigue sensation related to the classical conditioning. The classical conditioning of physical fatigue sensation in humans has also been reported [186]. Eight healthy male volunteers participated in this study. The experimental design of this study was the same as the previous one except for the conditioning session: they performed a hand grip task for $10 \mathrm{~min}$, and the metronome sounds were started $5 \mathrm{~min}$ after the task started. Similar to the previous study, fatigue sensation was caused by listening to the metronome sounds after the conditioning session and the ECD in the PCC was observed only in the second MEG session in all participants. These findings suggest that mental and physical fatigue sensation can be classically conditioned in humans in experimental settings, and that the PCC and IC seem to be involved in the neural mechanisms of classical conditioning related to mental and physical fatigue sensation. Taking these findings into consideration, the PCC and IC are involved in the neural mechanisms of inhibition systems and seem to play important roles in the pathophysiology of chronic fatigue (Fig. 4).

\section{Conclusion}

Information related to the mechanisms underlying fatigue is still not complete. A major obstacle to this understanding involves limitations in our evaluation methods to understand the complex, dynamic, and interactive nature of fatigue. Several challenges, in particular advanced human behavioral, physiological, and neuroimaging studies, need 


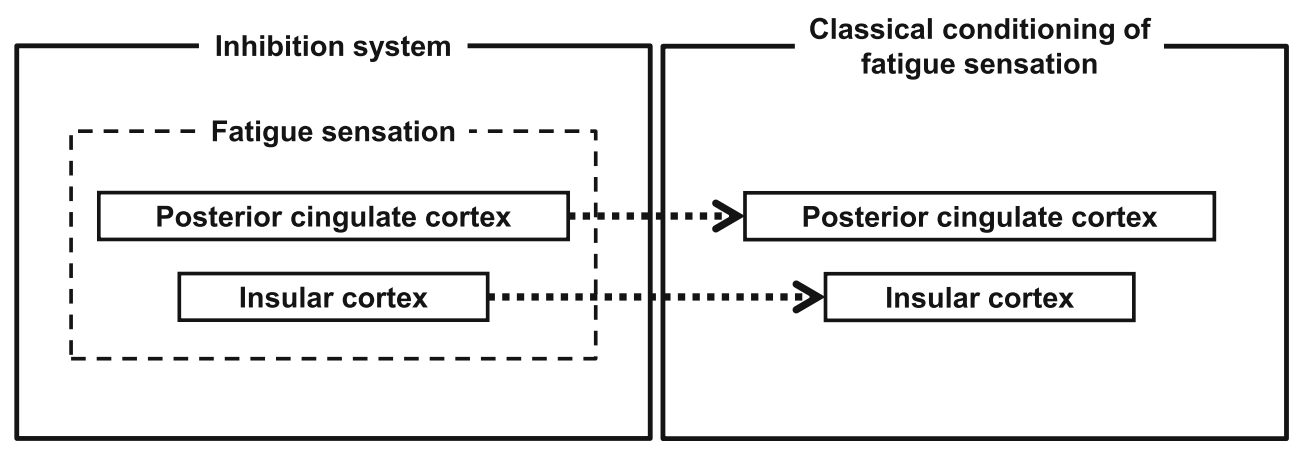

Fig. 4 The brain regions involved in the neural mechanisms of fatigue sensation and those of classical conditioning of fatigue sensation. The neural mechanisms of fatigue sensation, which constitute the inhibition system of fatigue, include the posterior

to be met to obtain sufficient information to understand the mechanisms underlying fatigue.

The best treatment for any disease is to prevent the disease before it occurs. In this sense, based on the risk or predictive factors for a disease, early selection of a highrisk group and intensive preventive interventions for this group would be an efficient preventive strategy for the disease. In particular, the importance of developing individualized preventive strategies should be emphasized. If sufficient intervention is not performed, the disease will likely develop. However, it is difficult to select the best preventive method for chronic fatigue, as few data are available to predict future disease. It would thus be beneficial to differentially diagnose future disease for each subject based on the subject's individual information, including symptomatic, historical, familial, physical, laboratory, behavioral, physiological, molecular imaging, and neuroimaging data and to perform a preventive intervention focusing on the disease, referred to as pre-emptive medicine. We refer to this predictive diagnostic method as 'predictive differential diagnosis' [24, 80]. To establish these preventive strategies, future well-designed, prospective cohort studies involving a large number of participants in several countries are essential. Because chronic fatigue is a contributing factor to various diseases [187-189], it should be a key target condition for pre-emptive medicine. This pre-emptive medicine may be a promising and strong strategy for health promotion.

In this review, we showed the frontier on fatigue, autonomic nerve dysfunction, and sleep-rhythm disorder, primarily based on the results of recent behavioral, neurophysiological, and neuroimaging studies. These findings provide new perspectives on the mechanisms underlying fatigue and on overcoming it, although future studies are needed.

Acknowledgments This work was supported by the Ministry of Health, Labour and Welfare of Japan (Grant number H25-Shinkei/ cingulate and insular cortices. The posterior cingulate and insular cortices are also involved in the neural mechanisms of the classical conditioning of fatigue sensation

Kin-Ippan-006 to Y.W.). This work was also supported by a Grant-inAid for Scientific Research (A) (Grant number $15 \mathrm{H} 02502$ to Y.W.) (B) (Grant numbers 25282211 and 26282189 to K.M. and 26282185 to M.T.), Research Activity Start-up (Grant number 10020007 to A.I.), Scientific Research on Innovative Areas "Constructive Developmental Science" (Grant number 24119004 to S.T.), and for Young Scientists (B) (Grant numbers 23700804 and 25750351 to A.I.) from the Ministry of Education, Culture, Sports, Science and Technology (MEXT) of Japan. We organized an integrated research project titled "The molecular/neural mechanisms of fatigue and fatigue sensation and the way to overcome chronic fatigue" under the control of the Ministry of Education, Culture, Sports, Science, and Technology (MEXT), Japanese Government, and carried it out from 1999 to 2005. This research project was followed by the 21 st Century COE program "Base to overcome fatigue", from 2005 to 2009 and the Grant-in-Aid for Scientific Research (A), from 2015 to 2020, supported by MEXT. We would like to thank Forte Science Communications for editorial assistance with the manuscript.

\section{Compliance with ethical standards}

Conflict of interest The authors declare that we have no conflict of interest.

Open Access This article is distributed under the terms of the Creative Commons Attribution 4.0 International License (http://crea tivecommons.org/licenses/by/4.0/), which permits unrestricted use, distribution, and reproduction in any medium, provided you give appropriate credit to the original author(s) and the source, provide a link to the Creative Commons license, and indicate if changes were made.

\section{References}

1. Kanaya N, Hirata N, Kurosawa S, Nakayama M, Namiki A (2003) Differential effects of propofol and sevoflurane on heart rate variability. Anesthesiology 98:34-40

2. Takusagawa M, Komori S, Umetani K, Ishihara T, Sawanobori T, Kohno I, Sano S, Yin D, Ijiri H, Tamura K (1999) Alterations of autonomic nervous activity in recurrence of variant angina. Heart 82:75-81

3. No authors listed (1996) Heart rate variability: standards of measurement, physiological interpretation and clinical use. Task Force of the European Society of Cardiology and the North American Society of Pacing and Electrophysiology. Circulation 93:1043-1065 
4. Akselrod S, Gordon D, Ubel FA, Shannon DC, Barger AC, Cohen RJ (1981) Power spectrum analysis of heart rate fluctuation: a quantitative probe of beat-to-beat cardiovascular control. Science 213:220-222

5. Pomeranz B, Macaulay RJ, Caudill MA, Kutz I, Adam D, Gordon D, Kilborn KM, Barger AC, Shannon DC, Cohen RJ et al (1985) Assessment of autonomic function in humans by heart rate spectral analysis. Am J Physiol 248:151-153

6. Malliani A, Pagani M, Lombardi F, Cerutti S (1991) Cardiovascular neural regulation explored in the frequency domain. Circulation 84:482-492

7. Appel ML, Berger RD, Saul JP, Smith JM, Cohen RJ (1989) Beat to beat variability in cardiovascular variables: noise or music? J Am Coll Cardiol 14:1139-1148

8. Pagani M, Montano N, Porta A, Malliani A, Abboud FM, Birkett C, Somers VK (1997) Relationship between spectral components of cardiovascular variabilities and direct measures of muscle sympathetic nerve activity in humans. Circulation 95:1441-1448

9. Tanaka M, Mizuno K, Tajima S, Sasabe T, Watanabe Y (2009) Central nervous system fatigue alters autonomic nerve activity. Life Sci 84:235-239

10. Tanaka M, Mizuno K, Yamaguti K, Kuratsune H, Fujii A, Baba H, Matsuda K, Nishimae A, Takesaka T, Watanabe Y (2011) Autonomic nervous alterations associated with daily level of fatigue. Behav Brain Funct 7:46

11. Mizuno K, Tanaka M, Yamaguti K, Kajimoto O, Kuratsune H, Watanabe Y (2011) Mental fatigue caused by prolonged cognitive load associated with sympathetic hyperactivity. Behav Brain Funct 7:17

12. Chalder T, Berelowitz G, Pawlikowska T, Watts L, Wessely S, Wright D, Wallace EP (1993) Development of a fatigue scale. J Psychosom Res 37:147-153

13. Tanaka M, Fukuda S, Mizuno K, Kuratsune H, Watanabe $Y$ (2009) Stress and coping styles are associated with severe fatigue in medical students. Behav Med 35:87-92

14. Tanaka M, Fukuda S, Mizuno K, Imai-Matsumura K, Jodoi T, Kawatani J, Takano M, Miike T, Tomoda A, Watanabe Y (2008) Reliability and validity of the Japanese version of the Chalder Fatigue Scale among youth in Japan. Psychol Rep 103:682-690

15. Afari N, Buchwald D (2003) Chronic fatigue syndrome: a review. Am J Psychiatry 160:221-236

16. Wyller VB, Saul JP, Amlie JP, Thaulow E (2007) Sympathetic predominance of cardiovascular regulation during mild orthostatic stress in adolescents with chronic fatigue. Clin Physiol Funct Imaging 27:231-238

17. Burton AR, Rahman K, Kadota Y, Lloyd A, Vollmer-Conna U (2010) Reduced heart rate variability predicts poor sleep quality in a case-control study of chronic fatigue syndrome. Exp Brain Res 204:71-78

18. Yamaguti K, Sasabe T, Kuratsune H, Nishizawa Y, Watanabe Y (2008) J Therapy 90:537-547 (in Japanese)

19. Tomoda A, Mizuno K, Murayama N, Joudoi T, Igasaki T, Miyazaki M, Miike T (2007) Event-related potentials in Japanese childhood chronic fatigue syndrome. J Pediatr Neurol 5:199-208

20. Benarroch EE (1997) The central autonomic network. In: Low PA (ed) Clinical autonomic disorder, 2nd edn. LippincottRaven, Philadelphia

21. Loewy AD (1990) Central autonomic pathways. In: Loewy AD, Spyer KM (eds) Central regulation of autonomic functions. Oxford Univ Press, New York

22. Critchley HD, Mathias CJ, Josephs O, O'Doherty J, Zanini S, Dewar BK, Cipolotti L, Shallice T, Dolan RJ (2003) Human cingulate cortex and autonomic control: converging neuroimaging and clinical evidence. Brain 126:2139-2152
23. Koski L, Paus T (2000) Functional connectivity of the anterior cingulate cortex within the human frontal lobe: a brain-mapping meta-analysis. Exp Brain Res 133:55-65

24. Paus T, Castro-Alamancos MA, Petrides M (2001) Corticocortical connectivity of the human mid-dorsolateral frontal cortex and its modulation by repetitive transcranial magnetic stimulation. Eur J Neurosci 14:1405-1411

25. Petrides M, Pandya DN (1999) Dorsolateral prefrontal cortex: comparative cytoarchitectonic analysis in the human and the macaque brain and corticocortical connection patterns. Eur $\mathbf{J}$ Neurosci 11:1011-1036

26. Vogt BA, Pandya DN (1987) Cingulate cortex of the rhesus monkey: II. Cortical afferents. J Comp Neurol 262:271-289

27. Amat J, Baratta MV, Paul E, Bland ST, Watkins LR, Maier SF (2005) Medial prefrontal cortex determines how stressor controllability affects behavior and dorsal raphe nucleus. Nat Neurosci 8:365-371

28. Thayer JF, Sternberg E (2006) Beyond heart rate variability: vagal regulation of allostatic systems. Ann N Y Acad Sci 1088:361-372

29. Thayer JF (2006) On the importance of inhibition: central and peripheral manifestations of nonlinear inhibitory processes in neural systems. Dose Response 4:2-21

30. Boksem MA, Meijman TF, Lorist MM (2006) Mental fatigue, motivation and action monitoring. Biol Psychol 72:123-132

31. Tanaka M, Sadato N, Okada T, Mizuno K, Sasabe T, Tanabe HC, Saito DN, Onoe H, Kuratsune H, Watanabe Y (2006) Reduced responsiveness is an essential feature of chronic fatigue syndrome: a fMRI study. BMC Neurol 6:9

32. Mizuno K, Tanaka M, Tanabe HC, Sadato N, Watanabe Y (2012) The neural substrates associated with attentional resources and difficulty of concurrent processing of the two verbal tasks. Neuropsychologia 50:1998-2009

33. Tajima S, Yamamoto S, Tanaka M, Kataoka Y, Iwase M, Yoshikawa E, Okada H, Onoe H, Tsukada H, Kuratsune H, Ouchi Y, Watanabe Y (2010) Medial orbitofrontal cortex is associated with fatigue sensation. Neurol Res Int 2010:671421

34. Caseras X, Mataix-Cols D, Rimes KA, Giampietro V, Brammer M, Zelaya F, Chalder T, Godfrey E (2008) The neural correlates of fatigue: an exploratory imaginal fatigue provocation study in chronic fatigue syndrome. Psychol Med 38:941-951

35. Okada T, Tanaka M, Kuratsune H, Watanabe Y, Sadato N (2004) Mechanisms underlying fatigue: a voxel-based morphometric study of chronic fatigue syndrome. BMC Neurol 4:14

36. Mizuno K, Tajima K, Watanabe Y, Kuratsune H (2014) Fatigue correlates with the decrease in parasympathetic sinus modulation induced by a cognitive challenge. Behav Brain Funct 10:25

37. Mizuno K, Tanaka M, Fukuda S, Imai-Matsumura K, Watanabe Y (2011) Relationship between cognitive functions and prevalence of fatigue in elementary and junior high school students. Brain Dev 33:470-479

38. Tajima K, Tanaka M, Mizuno K, Okada N, Rokushima K, Watanabe Y (2008) Effects of bathing in micro-bubbles on recovery from moderate mental fatigue. Ergonomia IJE\&HF 30:134-145

39. Watanabe Y, Sasabe T, Yamaguti K, Kobayashi M, Yamamoto S, Kuratsune H, Sano K, Hatanaka A, Tsukada H, Onoe H (2005) Prevention and/or recovery effects by green odor(s) on fatigue and green-odor-responsible brain regions as revealed by PET. Chem Senses Suppl 1:i268-i269

40. Sasabe T, Kobayashi M, Kondo Y, Onoe H, Matsubara S, Yamamoto S, Tsukada H, Onoe K, Watabe H, Iida H, Kogo M, Sano K, Hatanaka A, Sawada T, Watanabe Y (2003) Activation of the anterior cingulate gyrus by 'Green Odor': a positron emission tomography study in the monkey. Chem Senses 28:565-572 
41. Morriss R, Sharpe M, Sharpley AL, Cowen PJ, Hawton K, Morris J (1993) Abnormalities of sleep in patients with the chronic fatigue syndrome. BMJ 306:1161-1164

42. Watson NF, Kapur V, Arguelles LM, Goldberg J, Schmidt DF, Armitage R, Buchwald D (2003) Comparison of subjective and objective measures of insomnia in monozygotic twins discordant for chronic fatigue syndrome. Sleep 26:324-328

43. Watson NF, Jacobsen C, Goldberg J, Kapur V, Buchwald D (2004) Subjective and objective sleepiness in monozygotic twins discordant for chronic fatigue syndrome. Sleep 27:973-977

44. Neu D, Mairesse O, Hoffmann G, Dris A, Lambrecht LJ, Linkowski P, Verbanck P, Le Bon O (2007) Sleep quality perception in the chronic fatigue syndrome: correlations with sleep efficiency, affective symptoms and intensity of fatigue. Neuropsychobiology 56:40-46

45. Armitage R, Landis C, Hoffmann R, Lentz M, Watson N, Goldberg J, Buchwald D (2009) Power spectral analysis of sleep EEG in twins discordant for chronic fatigue syndrome. J Psychosom Res 66:51-57

46. Rahman K, Burton A, Galbraith S, Lloyd A, Vollmer-Conna U (2011) Sleep-wake behavior in chronic fatigue syndrome. Sleep 34:671-678

47. Morriss RK, Wearden AJ, Battersby L (1997) The relation of sleep difficulties to fatigue, mood and disability in chronic fatigue syndrome. J Psychosom Res 42:597-605

48. Unger ER, Nisenbaum R, Moldofsky H, Cesta A, Sammut C, Reyes M, Reeves WC (2004) Sleep assessment in a populationbased study of chronic fatigue syndrome. BMC Neurol 19:6

49. Kop WJ, Lyden A, Berlin AA, Ambrose K, Olsen C, Gracely RH, Williams DA, Clauw DJ (2005) Ambulatory monitoring of physical activity and symptoms in fibromyalgia and chronic fatigue syndrome. Arthritis Rheum 52:296-303

50. Hossain JL, Reinish LW, Kayumov L, Bhuiya P, Shapiro CM (2003) Underlying sleep pathology may cause chronic high fatigue in shift-workers. J Sleep Res 12:223-230

51. Sharpley A, Clements A, Hawton K, Sharpe M (1997) Do patients with "pure" chronic fatigue syndrome (neurasthenia) have abnormal sleep? Psychosom Med 59:592-596

52. Stores G, Fry A, Crawford C (1998) Sleep abnormalities demonstrated by home polysomnography in teenagers with chronic fatigue syndrome. J Psychosom Res 45:85-91

53. Tajima S, Kuratsune H, Yamaguti K, Takahashi A, Takashima S, Watanabe Y, Nishizawa Y (2007) Estimation of fatigue state in patient with CFS using actigraph and R-R interval power spectrum analysis. Nihon Rinsho 65:1057-1064 (in Japanese)

54. Ohinata J, Suzuki N, Araki A, Takahashi S, Fujieda K, Tanaka H (2008) Actigraphic assessment of sleep disorders in children with chronic fatigue syndrome. Brain Dev 30:329-333

55. Aerenhouts D, Ickmans K, Clarys P, Zinzen E, Meersdom G, Lambrecht L, Nijs J (2014) Sleep characteristics, exercise capacity and physical activity in patients with chronic fatigue syndrome. Disabil Rehabil 16:1-7

56. Ball N, Buchwald DS, Schmidt D, Goldberg J, Ashton S, Armitage R (2004) Monozygotic twins discordant for chronic fatigue syndrome: objective measures of sleep. J Psychosom Res 56:207-212

57. Fossey M, Libman E, Bailes S, Baltzan M, Schondorf R, Amsel R, Fichten CS (2004) Sleep quality and psychological adjustment in chronic fatigue syndrome. J Behav Med 27:581-605

58. Reeves WC, Heim C, Maloney EM, Youngblood LS, Unger ER, Decker MJ, Jones JF, Rye DB (2006) Sleep characteristics of persons with chronic fatigue syndrome and non-fatigued controls: results from a population-based study. BMC Neurol 16:41

59. Guilleminault C, Poyares D, Rosa Ad, Kirisoglu C, Almeida T, Lopes MC (2006) Chronic fatigue, unrefreshing sleep and nocturnal polysomnography. Sleep Med 7:513-520
60. Kishi A, Struzik ZR, Natelson BH, Togo F, Yamamoto Y (2008) Dynamics of sleep stage transitions in healthy humans and patients with chronic fatigue syndrome. Am J Physiol Regul Integr Comp Physiol 294:R1980-R1987

61. Decker MJ, Tabassum H, Lin JM, Reeves WC (2009) Electroencephalographic correlates of chronic fatigue syndrome. Behav Brain Funct 6:43

62. Neu D, Cappeliez B, Hoffmann G, Verbanck P, Linkowski P, Le Bon O (2009) High slow-wave sleep and low-light sleep: chronic fatigue syndrome is not likely to be a primary sleep disorder. J Clin Neurophysiol 26:207-212

63. Le Bon O, Neu D, Berquin Y, Lanquart JP, Hoffmann R, Mairesse O, Armitage R (2012) Ultra-slow delta power in chronic fatigue syndrome. Psychiatry Res 200:742-747

64. Neu D, Mairesse O, Verbanck P, Le Bon O (2015) Slow wave sleep in the chronically fatigued: Power spectra distribution patterns in chronic fatigue syndrome and primary insomnia. Clin Neurophysiol. doi:10.1016/j.clinph.2014.12.016

65. Kishi A, Natelson BH, Togo F, Struzik ZR, Rapoport DM, Yamamoto Y (2011) Sleep-stage dynamics in patients with chronic fatigue syndrome with or without fibromyalgia. Sleep 34:1551-1560

66. Gotts ZM, Deary V, Newton J, Van der Dussen D, De Roy P, Ellis JG (2013) Are there sleep-specific phenotypes in patients with chronic fatigue syndrome? A cross-sectional polysomnography analysis. BMJ Open. doi:10.1136/bmjopen-2013-002999

67. Mariman A, Vogelaers D, Hanoulle I, Delesie L, Pevernagie D (2012) Subjective sleep quality and daytime sleepiness in a large sample of patients with chronic fatigue syndrome (CFS). Acta Clin Belg 67:19-24

68. Togo F, Natelson BH, Cherniack NS, FitzGibbons J, Garcon C, Rapoport DM (2008) Sleep structure and sleepiness in chronic fatigue syndrome with or without coexisting fibromyalgia. Arthritis Res Ther 10:R56

69. Ohashi K, Yamamoto Y, Natelson BH (2002) Activity rhythm degrades after strenuous exercise in chronic fatigue syndrome. Physiol Behav 77:39-44

70. Togo F, Natelson BH, Cherniack NS, Klapholz M, Rapoport DM, Cook DB (2010) Sleep is not disrupted by exercise in patients with chronic fatigue syndromes. Med Sci Sports Exerc 42:16-22

71. Kishi A, Togo F, Cook DB, Klapholz M, Yamamoto Y, Rapoport DM, Natelson BH (2013) The effects of exercise on dynamic sleep morphology in healthy controls and patients with chronic fatigue syndrome. Physiol Rep 1:e00152

72. Tomoda A, Miike T, Uezono K, Kawasaki T (1994) A school refusal case with biological rhythm disturbance and melatonin therapy. Brain Dev 16:71-76

73. van Heukelom RO, Prins JB, Smits MG, Bleijenberg G (2006) Influence of melatonin on fatigue severity in patients with chronic fatigue syndrome and late melatonin secretion. Eur $\mathbf{J}$ Neurol 13:55-60

74. Williams G, Pirmohamed J, Minors D, Waterhouse J, Buchan I, Arendt J, Edwards RH (1996) Dissociation of body-temperature and melatonin secretion circadian rhythms in patients with chronic fatigue syndrome. Clin Physiol 16:327-337

75. Tomoda A, Miike T, Yonamine K, Adachi K, Shiraishi S (1997) Disturbed circadian core body temperature rhythm and sleep disturbance in school refusal children and adolescents. Biol Psychiatry 41:810-813

76. Hamilos DL, Nutter D, Gershtenson J, Ikle D, Hamilos SS, Redmond DP, Di Clementi JD, Schmaling KB, Jones JF (2001) Circadian rhythm of core body temperature in subjects with chronic fatigue syndrome. Clin Physiol 21:184-195

77. Ohashi K, Bleijenberg G, van der Werf S, Prins J, Amaral LA, Natelson BH, Yamamoto Y (2004) Decreased fractal correlation 
in diurnal physical activity in chronic fatigue syndrome. Methods Inf Med 43:26-29

78. Tajima S (2009) Physiological fatigue estimation using physical activity analysis. Igaku No Ayumi 228:640-645 (in Japanese)

79. Kawabata M, Ueno T, Tomita J, Kawatani J, Tomoda A, Kume S, Kume K (2013) Temporal organization of rest defined by actigraphy data in healthy and childhood chronic fatigue syndrome children. BMC Psychiatry 13:281

80. Takimoto M, Hamada A, Tomoda A, Ohdo S, Ohmura T, Sakato H, Kawatani J, Jodoi T, Nakagawa H, Terazono H, Koyanagi S, Higuchi S, Kimura M, Tukikawa H, Irie S, Saito H, Miike T (2005) Daily expression of clock genes in whole blood cells in healthy subjects and a patient with circadian rhythm sleep disorder. Am J Physiol Regul Integr Comp Physiol 289:R1273R1279

81. Boneva RS, Decker MJ, Maloney EM, Lin JM, Jones JF, Helgason HG, Heim CM, Rye DB, Reeves WC (2007) Higher heart rate and reduced heart rate variability persist during sleep in chronic fatigue syndrome: a population-based study. Auton Neurosci 137:94-101

82. Yamaguti K, Tajima S, Kuratsune H (2013) Autonomic dysfunction in chronic fatigue syndrome. Adv Neuroimmun Biol 4:281-289

83. Tomoda A, Miike T, Honda T, Fukuda K, Kai Y, Nabeshima M, Takahashi M (1995) Single-photon emission computed tomography for cerebral blood flow in school phobia. Curr Ther Res 56:1088-1093

84. Tomoda A, Miike T, Yamada E, Honda H, Moroi T, Ogawa M, Ohtani Y, Morishita S (2000) Chronic fatigue syndrome in childhood. Brain Dev 22:60-64

85. Gotts ZM, Ellis JG, Deary V, Barclay N, Newton JL (2015) The association between daytime napping and cognitive functioning in chronic fatigue syndrome. PLoS One 10:e0117136. doi:10. 1371/journal.pone.0117136

86. Richards RS, Roberts TK, McGregor NR, Dunstan RH, Butt HL (2000) Blood parameters indicative of oxidative stress are associated with symptom expression in chronic fatigue syndrome. Redox Rep 5:35-41

87. Tomoda A, Joudoi T, el-M Rabab, Matsumoto T, Park TH, Miike T (2005) Cytokine production and modulation: comparison of patients with chronic fatigue syndrome and normal controls. Psychiatry Res 134:101-104

88. Nakamura T, Schwander S, Donnelly R, Cook DB, Ortega F, Togo F, Yamamoto Y, Cherniack NS, Klapholz M, Rapoport D, Natelson BH (2013) Exercise and sleep deprivation do not change cytokine expression levels in patients with chronic fatigue syndrome. Clin Vaccine Immunol 20:1736-1742

89. Iwatani N, Miike T, Kai Y, Kodama M, Mabe H, Tomoda A, Fukuda K, Jyodoi T (1997) Glucoregulatory disorders in school refusal students. Clin Endocrinol 47:273-278

90. Taylor JL, Gandevia SC (2008) A comparison of central aspects of fatigue in submaximal and maximal voluntary contractions. J Appl Physiol 104:542-550

91. Taylor JL, Butler JE, Allen GM, Gandevia SC (1996) Changes in motor cortical excitability during human muscle fatigue. J Physiol 490:519-528

92. Johnston J, Rearick M, Slobounov S (2001) Movement-related cortical potentials associated with progressive muscle fatigue in a grasping task. Clin Neurophysiol 112:68-77

93. Liu JZ, Lewandowski B, Karakasis C, Yao B, Siemionow V, Sahgal V, Yue GH (2007) Shifting of activation center in the brain during muscle fatigue: an explanation of minimal central fatigue? Neuroimage 35:299-307

94. Dettmers C, Lemon RN, Stephan KM, Fink GR, Frackowiak RS (1996) Cerebral activation during the exertion of sustained static force in man. Neuroreport 7:2103-2110
95. Korotkov A, Radovanovic S, Ljubisavljevic M, Lyskov E, Kataeva G, Roudas M, Pakhomov S, Thunberg J, Medvedev S, Johansson H (2005) Comparison of brain activation after sustained non-fatiguing and fatiguing muscle contraction: a positron emission tomography study. Exp Brain Res 163:65-74

96. Liu JZ, Shan ZY, Zhang LD, Sahgal V, Brown RW, Yue GH (2003) Human brain activation during sustained and intermittent submaximal fatigue muscle contractions: an FMRI study. J Neurophysiol 90:300-312

97. Benwell NM, Mastaglia FL, Thickbroom GW (2006) Reduced functional activation after fatiguing exercise is not confined to primary motor areas. Exp Brain Res 175:575-583

98. Benwell NM, Mastaglia FL, Thickbroom GW (2007) Changes in the functional MR signal in motor and non-motor areas during intermittent fatiguing hand exercise. Exp Brain Res 18:93-97

99. Post M, Steens A, Renken R, Maurits NM, Zijdewind I (2009) Voluntary activation and cortical activity during a sustained maximal contraction: an fMRI study. Hum Brain Mapp 30:1014-1027

100. Logothetis NK (2008) What we can do and what we cannot do with fMRI. Nature 453:869-878

101. Shibasaki H (2008) Human brain mapping: hemodynamic response and electrophysiology. Clin Neurophysiol 119: 731-743

102. Tanji J, Okano K, Sato KC (1988) Neuronal activity in cortical motor areas related to ipsilateral, contralateral, and bilateral digit movements of the monkey. J Neurophysiol 60:325-343

103. Tanaka M, Ishii A, Watanabe Y (2013) Neural mechanism of facilitation system during physical fatigue. PLoS One 8:80731

104. Tanaka M, Watanabe Y (2011) Neural compensation mechanisms to regulate motor output during physical fatigue. Brain Res 1395:46-52

105. Tanaka M, Ishii A, Watanabe Y (2014) Regulatory mechanism of performance in chronic cognitive fatigue. Med Hypotheses 82:567-571

106. Alexander GE, Crutcher MD (1990) Functional architecture of basal ganglia circuits: neural substrates of parallel processing. Trends Neurosci 13:266-271

107. Tanaka M, Watanabe Y (2012) Supraspinal regulation of physical fatigue. Neurosci Biobehav Rev 36:727-734

108. Desmond P, Hancock P (2001) Active and passive fatigue states. In: Hancock P, Desmond P (eds) Stress, workload, and fatigue. Lawrence Erlbaum Associates, New Jersey

109. Matthews G, Desmond PA (2002) Task-induced fatigue states and simulated driving performance. Q J Exp Psychol A 55:659-686

110. Mizuno K, Watanabe Y (2007) Utility of an advanced trail making test as a neuropsychological tool for an objective evaluation of work efficiency during mental fatigue. In: Watanabe Y, Evengård B, Natelson B, Jason L, Kuratsune H (eds) Fatigue science for human health. Springer, New York

111. Tanaka M, Ishii A, Watanabe Y (2014) Neural effects of mental fatigue caused by continuous attention load: a magnetoencephalography study. Brain Res 1561:60-66

112. Ishii A, Tanaka M, Shigihara Y, Kanai E, Funakura M, Watanabe Y (2013) Neural effects of prolonged mental fatigue: a magnetoencephalography study. Brain Res 1529:105-112

113. Shigihara Y, Tanaka M, Ishii A, Tajima S, Kanai E, Funakura M, Watanabe Y (2013) Two different types of mental fatigue produce different styles of task performance. Neurol Psychiatr Brain Res 19:5-11

114. Shigihara Y, Tanaka M, Ishii A, Kanai E, Funakura M, Watanabe Y (2013) Two types of mental fatigue affect spontaneous oscillatory brain activities in different ways. Behav Brain Funct 9:2 
115. Tanaka M, Ishii A, Shigihara Y, Tajima S, Funakura M, Kanai E, Watanabe Y (2012) Impaired selective attention caused by mental fatigue. J Neurol Sci (Turkish) 29:542-553

116. Tanaka M, Shigihara Y, Ishii A, Funakura M, Kanai E, Watanabe Y (2012) Effect of mental fatigue on the central nervous system: an electroencephalography study. Behav Brain Funct 8:48

117. Kuratsune D, Tajima S, Koizumi J, Yamaguti K, Sasabe T, Mizuno K, Tanaka M, Okawa N, Mito H, Tsubone H, Watanabe $\mathrm{Y}$, Inoue M, Kuratsune H (2012) Changes in reaction time, coefficient of variance of reaction time, and autonomic nerve function in the mental fatigue state caused by long-term computerized Kraepelin test workload in healthy volunteers. World J Neurosci 2:113-118

118. Shigihara Y, Tanaka M, Watanabe Y (2010) Relationship between fatigue and photosensitivity. Behav Med 36:109-112

119. Kajimoto O (2007) Development of a method of evaluation of fatigue and its economic impacts. In: Watanabe $\mathrm{Y}$, Evengård $\mathrm{B}$, Natelson B, Jason L, Kuratsune H (eds) Fatigue science for human health. Springer, New York

120. Johnson SA, Yechiam E, Murphy RR, Queller S, Stout JC (2006) Motivational processes and autonomic responsivity in Asperger's disorder: evidence from the Iowa Gambling Task. JINS 12:668-676

121. Mezzacappa E, Kindlon D, Saul JP, Earls F (1998) Executive and motivational control of performance task behavior, and autonomic heart-rate regulation in children: physiologic validation of two-factor solution inhibitory control. J Child Psychol Psychiatry 39:525-531

122. Brookes MJ, Wood JR, Stevenson CM, Zumer JM, White TP, Liddle PF, Morris PG (2011) Changes in brain network activity during working memory tasks: a magnetoencephalography study. Neuroimage 55:1804-1815

123. Varela F, Lachaux JP, Rodriguez E, Martinerie J (2001) The brainweb: phase synchronization and large-scale integration. Nat Rev Neurosci 2:229-239

124. Lopes da Silva F (1991) Neural mechanisms underlying brain waves: from neural membranes to networks. Electroencephalogr Clin Neurophysiol 79:81-93

125. Rinzel J, Terman D, Wang X, Ermentrout B (1998) Propagating activity patterns in large-scale inhibitory neuronal networks. Science 279:1351-1355

126. Yanagisawa H, Dan I, Tsuzuki D, Kato M, Okamoto M, Kyutoku Y, Soya H (2010) Acute moderate exercise elicits increased dorsolateral prefrontal activation and improves cognitive performance with Stroop test. Neuroimage 50:1702-1710

127. Tanaka M, Ishii A, Watanabe Y (2014) Neural effect of mental fatigue on physical fatigue: a magnetoencephalography study. Brain Res 1542:49-55

128. Boksem MA, Tops M (2008) Mental fatigue: costs and benefits. Brain Res Rev 59:125-139

129. Lim J, Wu WC, Wang J, Detre JA, Dinges DF, Rao H (2010) Imaging brain fatigue from sustained mental workload: an ASL perfusion study of the time-on-task effect. Neuroimage 49:3426-3435

130. Ishii A, Tanaka M, Watanabe Y (2014) Neural mechanisms of mental fatigue. Rev Neurosci 25:469-479

131. Smith EE, Jonides J (1999) Storage and executive processes in the frontal lobes. Science 283:1657-1661

132. Carter CS, van Veen V (2007) Anterior cingulate cortex and conflict detection: an update of theory and data. Cogn Affect Behav Neurosci 7:367-379

133. Chaudhuri A, Behan PO (2000) Fatigue and basal ganglia. J Neurol Sci 179:34-42

134. Chaudhuri A, Behan PO (2004) Fatigue in neurological disorders. Lancet 363:978-988
135. Roelcke U, Kappos L, Lechner-Scott J, Brunnschweiler H, Huber S, Ammann W, Plohmann A, Dellas S, Maguire RP, Missimer J, Radu EW, Steck A, Leenders KL (1997) Reduced glucose metabolism in the frontal cortex and basal ganglia of multiple sclerosis patients with fatigue: a ${ }^{18} \mathrm{~F}$-fluorodeoxyglucose positron emission tomography study. Neurology 48:1566-1571

136. Filippi M, Rocca MA, Colombo B, Falini A, Codella M, Scotti G, Comi G (2002) Functional magnetic resonance imaging correlates of fatigue in multiple sclerosis. Neuroimage 15:559-567

137. White AT, Lee JN, Light AR, Light KC (2009) Brain activation in multiple sclerosis: a BOLD fMRI study of the effects of fatiguing hand exercise. Mult Scler 15:580-586

138. Sisto SA, LaManca J, Cordero DL, Bergen MT, Ellis SP, Drastal S, Boda WL, Tapp WN, Natelson BH (1996) Metabolic and cardiovascular effects of a progressive exercise test in patients with chronic fatigue syndrome. Am J Med 100:634-640

139. Gibson H, Carroll N, Clague JE, Edwards RH (1993) Exercise performance and fatiguability in patients with chronic fatigue syndrome. J Neurol Neurosurg Psychiatry 56:993-998

140. Chaudhuri A, Condon BR, Gow JW, Brennan D, Hadley DM (2003) Proton magnetic resonance spectroscopy of basal ganglia in chronic fatigue syndrome. Neuroreport 14:225-228

141. Kuratsune H, Yamaguti K, Lindh G, Evengård B, Hagberg G, Matsumura K, Iwase M, Onoe H, Takahashi M, Machii T, Kanakura Y, Kitani T, Långström B, Watanabe Y (2002) Brain regions involved in fatigue sensation: reduced acetylcarnitine uptake into the brain. Neuroimage 17:1256-1265

142. Siessmeier T, Nix WA, Hardt J, Schreckenberger M, Egle UT, Bartenstein P (2003) Observer independent analysis of cerebral glucose metabolism in patients with chronic fatigue syndrome. J Neurol Neurosurg Psychiatry 74:922-928

143. de Lange FP, Koers A, Kalkman JS, Bleijenberg G, Hagoort P, van der Meer JW, Toni I (2008) Increase in prefrontal cortical volume following cognitive behavioural therapy in patients with chronic fatigue syndrome. Brain 131:2172-2180

144. Tirelli U, Chierichetti F, Tavio M, Simonelli C, Bianchin G, Zanco P, Ferlin G (1998) Brain positron emission tomography (PET) in chronic fatigue syndrome: preliminary data. Am J Med 105:54-58

145. Shigihara Y, Tanaka M, Mizuno K, Ishii A, Yamano E, Funakura M, Kanai E, Watanabe Y (2012) Effects of daily levels of fatigue and acutely induced fatigue on the visual evoked magnetic response. Brain Res 1457:44-50

146. Tanaka M, Shigihara Y, Funakura M, Kanai E, Watanabe Y (2012) Fatigue-associated alterations of cognitive function and electroencephalographic power densities. PLoS One 7:34774

147. Shigihara Y, Tanaka M, Tsuyuguchi N, Tanaka H, Watanabe Y (2010) Hazardous nature of high-temporal-frequency strobe light stimulation: neural mechanisms revealed by magnetoencephalography. Neuroscience 166:482-490

148. Tanaka M, Ishii A, Watanabe Y (2014) Hazardous effects of light stimulation in the central nervous system. Austin J Clin Neurol 1:4

149. Lipton P (1999) Ischemic cell death in brain neurons. Physiol Rev 79:1431-1568

150. Yamano E, Tanaka M, Ishii A, Tsuruoka N, Abe K, Watanabe $Y$ (2013) Effects of chicken essence on recovery from mental fatigue in healthy males. Med Sci Monit 19:540-547

151. Mizuma H, Tanaka M, Nozaki S, Mizuno K, Tahara T, Ataka S, Sugino T, Shirai T, Kajimoto Y, Kuratsune H, Kajimoto O, Watanabe Y (2009) Daily oral administration of crocetin attenuates physical fatigue in human. Nutr Res 29:145-150

152. Tanaka M, Baba Y, Kataoka Y, Kinbara N, Sagesaka YM, Kakuda T, Watanabe Y (2008) Effects of (-)-epigallocatechin 
gallate in liver of an animal model of combined (physical and mental) fatigue. Nutrition 24:599-603

153. Tanaka M, Watanabe Y (2008) Reduced energy utilization in the brain is a feature of an animal model of fatigue. Int $\mathbf{J}$ Neurosci 118:683-692

154. Mizuno K, Tanaka M, Nozaki S, Mizuma H, Ataka S, Tahara T, Sugino T, Shirai T, Kajimoto Y, Kuratsune H, Kajimoto O, Watanabe Y (2008) Antifatigue effects of coenzyme Q10 during physical fatigue. Nutrition 24:293-299

155. Ataka S, Tanaka M, Nozaki S, Mizuma H, Mizuno K, Tahara T, Sugino T, Shirai T, Kajimoto Y, Kuratsune H, Kajimoto O, Watanabe Y (2008) Effects of oral administration of caffeine and D-ribose on mental fatigue. Nutrition 24:233-238

156. Ataka S, Tanaka M, Nozaki S, Mizuma H, Mizuno K, Tahara T, Sugino T, Shirai T, Kajimoto Y, Kuratsune H, Kajimoto O, Watanabe Y (2007) Effects of Applephenon and ascorbic acid on physical fatigue. Nutrition 23:419-423

157. Mizokawa S, Tanaka M, Matsumura A, Nozaki S, Watanabe Y (2003) Recovery from fatigue: changes in local brain $2-\left[{ }^{18-}\right.$ F]fluoro-2-deoxy-D-glucose utilization measured by autoradiography and in brain monoamine levels of rat. Neurosci Lett 353:169-172

158. Tanaka M, Nakamura F, Mizokawa S, Matsumura A, Nozaki S, Watanabe Y (2003) Establishment and assessment of a rat model of fatigue. Neurosci Lett 352:159-162

159. Arnett SV, Alleva LM, Korossy-Horwood R, Clark IA (2011) Chronic fatigue syndrome - a neuroimmunological model. Med Hypotheses 77:77-83

160. Pall ML (2000) Elevated, sustained peroxynitrite levels as the cause of chronic fatigue syndrome. Med Hypotheses 54:115-125

161. Tanaka M, Ishii A, Watanabe Y (2015) Fatigue in the central nervous system. Austin J Clin Neurol 2:1020

162. Tanaka M, Ishii A, Watanabe Y (2013) Neural dysfunction in chronic fatigue syndrome. Adv Neuroimmune Biol 4:291-300

163. Tanaka M, Ishii A, Watanabe Y (2013) Neural mechanisms underlying chronic fatigue. Rev Neurosci 24:617-628

164. Tanaka M, Watanabe Y (2012) Risk-management syndrome. Int J Psychiatry Clin Pract 16:312-315

165. Tanaka M, Watanabe Y (2010) A new hypothesis of chronic fatigue syndrome: co-conditioning theory. Med Hypotheses 75:244-249

166. Ishii A, Tanaka M, Yamano E, Watanabe Y (2012) Neural substrates activated by viewing others expressing fatigue: a magnetoencephalography study. Brain Res 1455:68-74

167. Wicker B, Keysers C, Plailly J, Royet JP, Gallese V, Rizzolatti G (2003) Both of us disgusted in My insula: the common neural basis of seeing and feeling disgust. Neuron 40:655-664

168. Singer T, Seymour B, O’Doherty J, Kaube H, Dolan RJ, Frith CD (2004) Empathy for pain involves the affective but not sensory components of pain. Science 303:1157-1162

169. Botvinick M, Jha AP, Bylsma LM, Fabian SA, Solomon PE, Prkachin KM (2005) Viewing facial expressions of pain engages cortical areas involved in the direct experience of pain. Neuroimage 25:312-319

170. Jabbi M, Swart M, Keysers C (2007) Empathy for positive and negative emotions in the gustatory cortex. Neuroimage 34:1744-1753

171. Cheng Y, Yang CY, Lin CP, Lee PL, Decety J (2008) The perception of pain in others suppresses somatosensory oscillations: a magnetoencephalography study. Neuroimage 40:1833-1840

172. Fabbri-Destro M, Rizzolatti G (2008) Mirror neurons and mirror systems in monkeys and humans. Physiology (Bethesda) 23:171-179

173. Bastiaansen JA, Thioux M, Keysers C (2009) Evidence for mirror systems in emotions. Philos Trans R Soc Lond B Biol Sci 364:2391-2404

174. Johnson SC, Baxter LC, Wilder LS, Pipe JG, Heiserman JE, Prigatano GP (2002) Neural correlates of self-reflection. Brain 125:1808-1814

175. Vogt BA, Laureys S (2005) Posterior cingulate, precuneal and retrosplenial cortices: cytology and components of the neural network correlates of consciousness. Prog Brain Res 150:205-217

176. Vogt BA, Vogt L, Laureys S (2006) Cytology and functionally correlated circuits of human posterior cingulate areas. Neuroimage 29:452-466

177. Ishii A, Tanaka M, Yamano E, Watanabe Y (2014) The neural substrates of physical fatigue sensation to evaluate ourselves: a magnetoencephalography study. Neuroscience 261:60-67

178. Ishii A, Tanaka M, Watanabe Y (2014) The neural substrates of self-evaluation of mental fatigue: a magnetoencephalography study. PLoS One 9:e95763

179. Ishii A, Tanaka M, Watanabe Y (2014) The neural mechanisms underlying the decision to rest in the presence of fatigue: a magnetoencephalography study. PLoS One 9:e109740

180. Otto T, Zijlstra FR, Goebel R (2013) Neural correlates of mental effort evaluation- involvement of structures related to selfawareness. Soc Cogn Affect Neurosci 9:307-315

181. Katafuchi T (2004) Conditioning of fatigue and serotonin system. Mol Med 41:1264-1268 (in Japanese)

182. Katafuchi T, Kondo T, Yasaka T, Kubo K, Take S, Yoshimura M (2003) Prolonged effects of polyriboinosinic:polyribocytidylic acid on spontaneous running wheel activity and brain interferon-alpha mRNA in rats: a model for immunologically induced fatigue. Neuroscience 120:837-845

183. Katafuchi T, Kondo T, Take S, Yoshimura M (2005) Enhanced expression of brain interferon-alpha and serotonin transporter in immunologically induced fatigue in rats. Eur $\mathbf{J}$ Neurosci 22:2817-2826

184. Katafuchi T, Kondo T, Take S, Yoshimura M (2006) Brain cytokines and the 5-HT system during poly I:C-induced fatigue. Ann N Y Acad Sci 1088:230-237

185. Ishii A, Tanaka M, Iwamae M, Kim C, Yamano E, Watanabe $Y$ (2013) Fatigue sensation induced by the sounds associated with mental fatigue and its related neural activities: revealed by magnetoencephalography. Behav Brain Funct 9:24

186. Tanaka M, Ishii A, Watanabe Y (2013) Neural correlates of central inhibition during physical fatigue. PLoS One 8:e70949

187. Koyama H, Fukuda S, Shoji T, Inaba M, Tsujimoto Y, Tabata T, Okuno S, Yamakawa T, Okada S, Okamura M, Kuratsune H, Fujii H, Hirayama Y, Watanabe Y, Nishizawa Y (2010) Fatigue is a predictor for cardiovascular outcomes in patients undergoing hemodialysis. Clin J Am Soc Nephrol 5:659-666

188. Covanis A, Stodieck SR, Wilkins AJ (2004) Treatment of photosensitivity. Epilepsia 45:40-45

189. Uehata T (2005) Nippon Rinsho 63:1249-1253 (in Japanese) 